О. Б. Каневская

канд. пед. наук, доцент

\title{
ОСОБЕННОСТИ ХУДОЖЕСТВЕННОЙ РЕЧИ В. М. ГАРШИНА
}

У статті проаналізовано особливості художнього мовлення видатного російського письменника В. М. Гаршина, визначено роль зображувальних засобів у його творах.

Всеволод Михайлович Гаршин (1855-1888) - выдающийся русский прозаик, автор двух небольших книжек рассказов, в которых, по словам Г. И. Успенского, «положительно исчерпано все содержание нашей жизни» [Цит. по 8, 164]. С его именем связан ряд художественных открытий: тематическое и стилистическое обновление жанра аллегории («Attalea princeps», «Красный цветок»), соединение в рамках лирической прозы романтических и реалистических принципов («Происшествие», «Ночь», «Трус», «Четыре дня»), преодоление натуралистических тенденций в социально-бытовом очерке («Денщик и офицер», «Из воспоминаний рядового Иванова»), мастерство художественной детали.

В своих произведениях В. Гаршин при помощи изобразительновыразительных средств создает неповторимые образы героев, время, когда происходят события, их место. Картины настолько красочны, эмоциональны и экспрессивны, что читателю кажется, будто он сам присутствует при происходящем, испытывает все чувства и ощущения, которые испытывают герои. Читатель вместе с персонажами произведений В. Гаршина переживает боль, страдания, голод, жажду, страх, борется за жизнь и побеждает. Эмоциональное воздействие художественной речи достигается, прежде всего, характером изображения персонажей и картин природы, поскольку в произведении выражается отношение автора к изображаемому.

В современной филологической науке общепризнано, что все стороны системы языка, каждое языковое явление в художественном произведении может приобретать поэтический характер, что художественную речь следует анализировать не только на уровне лексических значений, но и на 
уровне значений грамматических и словообразовательных, а также на уровне их звукового выражения.

Слово, выполняя свою эстетическую роль, является важнейшим средством создания художественного образа. В книге «Стилистика художественной речи», говоря о художественных произведениях, А. И. Ефимов пишет: «Каждое слово выступает в них тесно спаянным, слитым с изображаемыми картинами, образами и характерами, в силу чего оно приобретает особую эмоциональность и выразительность» [4, 48]. Иначе говоря, слово, будучи средством создания художественного образа, обнаруживает свою стилистическую способность - образность.

Однако, как отмечают исследователи, образность достигается не только метафоризацией, но и с помощью других средств (ритмики, мелодики, аллитерацией и т. д.). П. Г. Пустовойт указывает, что «грамматический фактор далеко не безразличен к образности: даже суффиксы и падежные окончания способны создавать стилистические различия» [7, 95]. И, наконец, качество образности и ее сила воздействия на читателя определяются творческой личностью писателя, остротой его наблюдения над жизнью, умением группировать детали своих наблюдений, оперировать всеми средствами создания образа, в том числе и словом.

Образность в художественном произведении немыслима вне слова, вне языкового оформления. Слова и выражения, при помощи которых пишущие могут ярко, образно, выразительно и кратко охарактеризовать те или иные признаки, или стороны предмета, или явления, являются изобразительно-выразительными средствами. С их помощью усиливается действенность высказывания благодаря тому, что к чисто логическому его содержанию добавляются различные экспрессивно-эмоциональные оттенки.

Большую роль в создании гаршинского стиля играют тропы: эпитеты, метафоры, олицетворения, аллегории, сравнения.

Излюбленный троп В.Гаршины - эпитеты. Например, с помощью эпитетов писатель смог подчеркнуть и передать весь ужас, который испытал главный герой в четырех днях, проведенных на поле битвы, размышления персонажа о войне и ее бессмысленности: Сидоров, молоденький солдатик первой роты («как я попал в нашу цель?» - мелькнуло у меня в голове»), вдруг присел к земле и молча оглянулся на меня большими испуганными глазами. Изо рта у него текла струйка крови. Дикие безумные хриплые вопли вырываются из моей груди, и нет на них ответа.

Для большей эмоциональности и экспрессивности речи автор использует такие группы эпитетов:

- оценочные: Совсем разбитый, одурманенный, я лежал почти в беспамятстве [3, 7]; ...они опутывали его...пропитывали все тело своим ужсасным содержанием [3, 180]; ...И призрачная борьба снова началась [3, 180]; ...и началась долгая борьба, утомительная для нападавших и мучительная для защищзающегося человека, тратившего остаток исто- 
щеннных сил [3, 181]; Он был страшен [3, 170]; ...я опять превратилась в скромную и конфузливую девочку... [3,29]; ...а третья - та уж совсем отвратительная, гнусная старуха [3, 18];

- описательные: ...была тихая, теплая и темная ночь; окно было открыто; звезды блестели на черном небе [3, 17]; Она горит весело и ясно и дымит с приятным, немного резким запахом [3, 18]; Но смерть не приходит и не берет меня. И я лежу под этим солнцем, и нет у меня глотка воды, чтоб освежить воспаленное горло [3, 5];

- характерологические: Из кустов глядят на меня добрые, голубые глаза Яковлева, нашего ефрейтора [3, 9]; Это командует Петр Иванович, наш лазаретный офицер, высокий, худой и очень добрый человек [3, 10]; ...тою же быстрою, тяжелою и решительною походкою, высоко подняв безумную голову, он вышел из конторы [3, 170]; Страшно бледный, с ввалившимися щеками, с глубоко ушедшими внутрь глазных впадин горящими глазами, он, уже шатающеюся походкой и часто спотыкаясь, продолжал свою бешеную ходьбу и говорил, говорил без конияа [3, 180];

- метафорические: Звезды ласково мигали лучами, пронимавшими до самого его сердца [3, 5]; Больной чувствовал, что из цүветка длинными, похожними на змей, ползучими потоками извивается зло... [3, 180]; Помнится утро с запахом соломы, которою топили дом [3, 15];

- цветовые: Бледно-розовые пятна заходили вокруг меня [3, 5]; Hесколько звезд смотрело из далекого чистого неба, одна из них была ярче всех и горела красноватым сиянием [3, 17]; ...звезды блестели на черном небе [3, 181]; Утки летели над сжатыми полями, над пожелтевшими лесами и над деревнями, полными хлеба в скирдах [3, 253]; Надо мной клочок черно-синего неба, на котором горит большая звезда и несколько маленьких, вокруг что-то темное, высокое [3, 5]; В этот яркий красный цуветок собралось все зло мира [3, 179].

Для стиля писателя характерна цветопись - использование в одном контексте нескольких цветовых эпитетов, что создает особую образность и придает описываемому объекту ощутимую зримость, красочность: ...почерневшая Нева. Скоро тронется лед, река будет голубая. Парк на той стороне зазеленеет. Острова также покроются зеленью [3, 27]; ...Обнажились сперва вериины бугров, зазеленела на них травка. Потом и вся степь зазеленела, хоть в оврагах еще лежал умиравший снег. Быстро...выросли кустики пионов, и на них пышные ярко-пурпуровые цзветы [3, 27]; На десятки верст протянулась широкая и дрожащчая серебряная полоса лунного света; остальное море было черно; ...ещуе более черные, чем самое море, силуэты судов покачивались на рейде... [3, 49]; ...свет их проходил сквозь массу голубоватой воды, кишащую рыбами..., наполненную растениями, резко выделявшимися на неопределенном фоне своими кроваво-красными, бурыми и грязно-зелеными силуэтами [3, 63]. 
Всеволод Гаршин довольно часто использует двойные (тройные) эпитеты, подобранные таким образом, что один компонент уточняет первый: Эти слова были сказаны громким, резким, звенящим голосом [3, 169]; Воспаленные, широко раскрытые глаза (он не спал десять суток) горели неподвижным горячим блеском;... спутанные курчавые волосы падали гривой на лоб; он быстрыми тяжелыми шагами ходил из угла в угол конторы [3, 170]; Его отнесли на койку в беспамятстве, которое перешло в глубокий, мертвый и долгий сон [3, 172]; Как мне хотелось вцепиться в его скверную смазливую белобрысую рожу! [3, 19].

Характерно для автора использование метафор как способа усиления изобразительных свойств художественной речи. Например: Червяк этот мысль: что дескать друг мой, не лжешь ли ты все это? [3, 18]; Говоришь горячо, как будто искренне, а в душе всегда сидит червяк, который точит и сосет $[3,18] ;$...в книге вместо букв - валящиеся ряды людей [3, 34]; Теперь он почувствовал, что в нем есть и другая сторона, та самая, о которой говорил ему робкий голос его души [3, 96]; Восторг этот родился в сердце, вырвался из него, хлынул горячей, широкой волной, разлился по всем членам, на мгновенье согрел и оживил закоченевшее несчастное существо [3, 100]; И пальма гордо смотрела зеленой вершиной на лес товарищей, раскинутых под нею [3, 83].

Частотны в прозе Гаршина и случаи олицетворения: $О н$ смотрел на них, отличая знакомые созвездия и радуясь тому, что они, как ему казалось, понимают его и сочувствуют ему [3, 180]; Луна жсалобно смотрит на меня круглым лицом [3, 10]; «Bот ты умрешь, умрешь, умрешь!»шепчут они (кусты) $[3,16]$; Угрюмо смотрят деревья на пальму $[3,85]$. Или: «Он воображает, что я расту для его удовольствия, - думала Attalea. - Пусть воображает!» [3,84]; Маленькая травка следила за борьбой и замирала от волнения [3, 85]. Писатель «одушевляет», «очеловечивает» и живые существа (птиц, животных, насекомых), и растения, и чувства человека. Внимательное, чуткое отношение к окружающему миру, проникновение вглубь человеческой души, художественно выраженное, это определяющая черта психологизма Всеволода Гаршина.

Еще одним тропом, встречающимся в прозе Гаршина, является аллегория - «изображение отвлеченного понятия или явления через конкретный образ» $[6,160]$. С именем писателя, как было отмечено выше, связано стилистическое обновление жанра аллегории вообще («Attalea princeps», «Красный цветок»), а также введение аллегорических образов в структуру произведений.

Так, аллегорией зла, ненависти является красный цветок в одноименном рассказе: Цветок в его глазах осуществлял собою все зло; он впитал в себя всю невинно пролитую кровь (оттого он и был так красен), все слезы, всю желчь человечества $[3,179]$; аллегорией войны и несчастья, ужаса - бык: Бык, на глазах которого убивают подобных ему быков, чувству- 
ет, вероятно, что-нибудь похожее... Он не понимает, чему его смерть послужит, и только с ужасом смотрит выкативиимися глазами на кровь и ревет отчаянным, надрывающим дуиу голосом [3, 34]. Стремления к свободе, вольнолюбия, любви к родной земле - пальма Attalea: Послушайте меня: растите выше и шире, раскидывайтесь ветви, напирайте на рамы и стекла, наша оранжерея рассыплется в куски, и мы выйдем на свободу... Я хочу увидеть небо и солнце не сквозь эти решетки и стекла, и я увижу!» [3, 82-83]. Оранжерея - аллегория тюрьмы, несвободы: Она (травка) не знала южной природы, но тоже любила воздух и свободу. Оранжнерея и для нее была тюрьмой [3, 83].

Сочетание нескольких тропов и стилистических фигур (аллегории, эпитетов, лексических повторов и др.) способствуют выражению в тексте глубоко нравственного содержания - гневного протеста против войны и зла, которое она несет людям: Кузьма кажется мне единицею, одной из тех, из которых составляются десятки тысяч, написанные в реляциях. Его болезнью и страданиями я пробую измерить зло, причиняемое войной. Сколько муки и тоски здесь, в одной комнате, на одной постели, в одной груди - и все это лишь капля в море горя и мук, испытываемых массою людей, которых посылают вперед, ворочают назад и кладут напоя грудами мертвых и ещзе стонущчих и копошащчихся окровавленных тел [3, 38].

Очень часто в прозе Гаршина встречаются и сравнения - прием, заключающийся в уподоблении одного предмета другому, в сопоставлении двух предметов или явлений, имеющих общий признак. Автор чаще всего вводит в высказывание сравнение с помощью служебных слов: как, точно, похожий: Жил так Аггей один, точно на высокой башне стоя [2, 370]; Идут они через толпу и дивятся на них все люди: идут, точно братья родные [2, 390]; [цветок]...точно два красных уголька [3, 177]; Kусть шевелятся и шелестят, точно разговаривают [3, 5]; Горло горит, жжет как огнем [3, 8]; Что-то острое и быстрое, как молния, пронизывает все мое тело от кожи к груди и голове, и я снова падаю $[3,5]$; ...он побледнел как смерть [3, 177]; ...Прежде чем их посадили, как сельдей в бочку, на пароход... [3, 11]; Его огромный диск... красен, как кровь [3, 14]; ...наедут пушки и раздавят, как червяка $[3,5]$; ...зверек ...запьхтел, как паровая машина [3, 184]; Он (выгон) пестрел, как огромный ковер из лоскутьев [3, 118]; ...и смешно перебирал толстенькими лапами, похожсими на медвежьи [3, 184]; ...гору трупов, служащую пьедесталом грандиозным делам, которые занесут на странищь истории [3,34]; ...nеро кажется оружием, наносящим белой бумаге черные раны $[3,34]$; Внизу река, изгибаясь голубой лентой, тянется с севера на юг [3, 116]; Деревья уже оголились и представлялись какими-то безобразными мертвецами $[3,85]$.

При помощи развернутых сравнений автор вызывает яркие образы в воображении читателей; даёт возможность пережить все то, что пережи- 
вают герои и отождествить эти переживания с каким-нибудь явлением или предметом, как бы подчеркивает сравнением всю эмоциональность и экспрессивность переживания: ...все лицо точно осветило солнцем, как освещается мокрый и печальный луг, когда раздвинутся тучи, нависшие над ним, и дадут выглянуть солнышку [3, 30].

В. Гаршин активно использует стилистические возможности гиперболизации. Известно, что гипербола - это чрезмерное преувеличение. Писатель применяет ее для заострения внимания читателя, заставляя его «проникнуться» настроением, состоянием, чувствами своих персонажей: $(O$ изветке) Это было таинственное, страшное существо, противоположное богу, Ариман, принявший скромный и невинный вид. Нужно было сорвать его и убить [3, 179]; Он (труп) совсем распльлся. Мириады червей падают из него. Как они копошатся! [3, 16]; Двенадизать тысяч... Эта ичифра то носится передо мною в виде знаков, то растягивается бесконечной лентой, лежащих рядом трупов. Если их положить плечо с плечом, то составится дорога в восемь верст... [3, 34].

Употребление гипербол писателем, придающее художественной речи особую экспрессию, объясняется тем, что сильное чувство увеличивает то, чем оно возбуждено. А также гипербола способствует более емкому, зримому описанию окружающего мира: $О$ домашних животных нечего и говорить: скот крупный и мелкий прятался под навес, собака, вырыв себе под амбаром яму, улеглась туда и, полузакрыв глаза, прерывисто дымала, высунув розовый язык чуть не на пол-аршина [3, 116]; - Поди ты, братец, своим трудом! - сказал муравей притащчвший во время речи навозного жука, не смотря на жару, чудовищный кусок сухого стебелька $[3,113]$.

Можно встретить у Гаршина противоположный гиперболе стилистический прием - литоту - чрезмерное преуменьшение. Этот прием в художественной речи выполняет те же функции, что и гипербола: заострение внимания читателей: Я лежу, кажется, на животе и вижу перед собою только маленький кусочек земли. Несколько травинок муравей, ползущуий с одной стороны вниз головою какие-то кусочки сора от прошлогодней травы - вот весь мой мир [3, 6].

Еще В. В. Виноградов писал: «Писатель - носитель и творец национальной культуры речи. Пользуясь общенародным языком своего времени, он отбирает, комбинирует, и в соответствии со своим творческим замыслом - объединяет разные средства словарного состава и грамматического строя своего родного языка» $[1,183]$. Итак, слово в языке художественной литературы выступает, прежде всего, как выразительное средство языка. Как отмечает В. П. Ковалев, к языковым выразительным средствам относятся те, в которых так или иначе проявляется «природа» языка, сознательно используемая писателем с установкой на эстетически значимое творчество, именно языковое творчество $[5,5]$. Большого писателя отличает мастерское владение всеми средствами языка (и лексическими, и грамматическими, и фонетическими) в эстетических целях. 
Следует подчеркнуть, что Всеволод Гаршин отличается художественно целесообразным выразительным использованием языковых единиц в их значениях, звучаниях, формах и конструкциях, актуализацией таких экспрессивных средств, которые воздействуют на психику читателя, создают многоплановость восприятия художественных образов. Для стиля писателя характерно активное использование различных лексических средств (антонимов, синонимов, окрашенной лексики) для углубления образов, усиления экспрессивности речи.

В прозе Гаршина встречаются различные (семантические, стилистические, семантико-стилистические) синонимы, которые более точно выражают мысль, ее коммуникативную сущность, усиливают психологизм внутренней речи персонажей, помогают более выразительно передать их чувства, усиливают эмоциональность и экспрессивность повествования: $B$ прошлом нет опоры, потому что все ложь, все обман [3, 10]; Он вспомнил горе и страдание, какое довелось ему видеть в жизни, настоящее житейское горе, перед которым все его мучения в одиночку ничего не значили, и понял, что ему нужно идти туда, в это горе, взять на свою долю часть его, и только тогда в душе его настанет мир $[3,100]$. Синонимы в художественной речи Гаршина имеют яркую экспрессивную нагрузку: - Эта песня безотрадна и уныла, - говорил сам бледный человек, - само время напевает ее и, как будто бы назидание мне, напевает так удивительно однообразно [3, 10]; У Львовых тоска, уныние [3, 44]; Не верьте Нина Петровна! Все врет! Выдумывает! [3, 49]; Завизжала и заскрежетала граната, раздался выстрел [3, 49].

Выразительность художественной речи гаршинских произведений достигается, прежде всего, умелым использованием различных стилистических фигур: антитезой, повтором, риторическими восклицаниями и вопросами, парцелляцией, перифразом и др. Стилистические фигуры способствуют выразительной и краткой характеристике предметов, явлений. Это дает возможность читателю как можно глубже проникнуть в смысл написанного. При помощи выразительных средств мастер слова привлекает и заостряет внимание читателей, где это необходимо, усиливает впечатление, подталкивает к размышлениям и анализу, уточняет выраженные мысли и способствует их дальнейшему более глубокому выражению.

Так, В. Гаршин умело пользуется одним из ярких средств оживления художественной речи, способствующему более глубокому выражению мыслей и чувств своих персонажей, авторского «я», - явлением антонимии и таким стилистическим приемом, как антитеза. Приведем наиболее интересные примеры из его произведений: - Под такт их хода прошла вся жизнь кажущимся разнообразием с горем и радостью, с отчаяньем $и$ восторгом, с ненавистью и любовью [3, 10]; Он плакал и молился богу в промежутках между проклятиями, обращенными к своему врагу [3, 173]; Страшно; не могу больше жить за свой собственный страх и 
счет; нужно, непременно нужно связать себя с общей жсизнью, мучиться и радоваться, ненавидеть и любить не ради своего "я», все пожирающего и ничего взамен не дающего, а ради общей людям правды, которая есть в мире, что бы я там не кричал, и которая говорит душе, несмотря на все старания заглушить ее [3, 100]; Как мне обнищать и нищему обогатеть против меня? [2, 370].

Писатель умело вводит антонимы и для описания внешности персонажа: ...лоб узок и низок...; на огромном плоском лице сиротливо сидел крошечный круглый нос, хотя и задранный вверх, но не только не придававший лищу выражения высокомерия, а напротив, делавший его ещуе более жсалким; рот, в противность носу, был огромен... [3, 101].

Многочисленны в прозе Гаршина лексические повторы. Думается, что это обусловлено тем, что герои его рассказов часто находятся в состоянии душевного и психического срыва, в стрессовой ситуации (война, болезнь, сумасшествие), переживают состояние душевного катарсиса, духовно и эмоционально очищаются. Эмоциональное и психическое состояние его героев передается предельно достоверно и с психологической, и с художественной стороны. Например: Думаешь ли ты на самом деле то, что теперь думаешь; - Да, тогда думал именно то, что думал; Любил отияа и знал, что любишь; Да, тогда все казалось тем, как оно казалось [3, 88]; «Bom mbl умрешь, умрешь, умрешь!» - шепчут они (кусть). «Не увидишь, не увидишь, не увидишь!» - отвечают кустьл с другой сторонь [3, 16]; Думаешь-думаешь, оправдываешься-оправдываешься, а на дне души все что-то повторяет: виновата, виновата, виновата... [3, 39]; Василий Петрович ел и думал, думал и ел [3, 55]; - Колокол! - повторил он. - Зачем колокол? [3, 95].

Лексические повторы используются и в пейзажах (уточняют впечатление от увиденного, подчеркивают детали), и при описании монотонности существования, а также выражают авторское видение мира: Широкое снежное поле. Белье холмы окружают его, на них белые же, заиндевевиие деревья [3, 48]; Проходит день, проходит ночь. Все то жее. / Hacmynает утро. Все то жсе. Проходит еще день [3, 9]; Это правда. / - Правда! Нашлась правда в такую минуту! / А минута казалась неизбежной [3, 95]

Для большей выразительности речи В. Гаршин активно использует такие стилистические фигуры, как риторические вопросы и восклицания. Часто целью их употребления является стремление привлечь внимание читателя к определенной теме либо к определенной части этой темы. Риторические вопросы и восклицания вводятся писателем и во внутренние монологи героев, и в диалогическую речь, характерны они и для авторской речи: Правда, разве я знаю, что я такое на самом деле? Не знаешь разве, как славен я и богат? [2, 371]; - Послушай, это, наконец, ужасно! Неужели ты говоришь правду? Неужели ты не брезгаешь нечестными средствами для достижения этого комфорта?.. [3, 55]; Скучно, не правда ли? 
[3, 67]; Зачем верит? Верить-то мне нужно, необходимо нужно, но как поверить? [3, 68]; Буду ли я по-прежнему нюхать розу? Или сойду с рельсов? [3, 75]; Трус я или нет? [3, 34]; А если это - наши? О проклятые кустыз! Зачем вы обросли вокруг меня таким густым забором? [3, 15].

Характерны восклицательные предложения, отражающие эмоциональные переживания персонажей: восторг, радость, ожесточенность, нервное напряжение и т. д.: - Смотрите, смотрите! - кричали в другой деревне взрослье - вот чудо-то! [3, 254]; -Да, да, да! - прокричал он вслух, каждый раз злобно надавливая кулаком на край стола, - нужно же как-то выбраться из путаницы [3, 170]; Ударь их в сердие, лиши их сна, стань перед их глазами призраком! [3, 74]; А как хорома жизнь!.. Bы, воспоминания, не мучьте меня, оставьте меня!... Аx, тоска, тоска! [3, 11].

Частотен у В. Гаршина и такой стилистический прием, как парцелляция, которая усиливает напряженность речи персонажей, находящихся в состоянии душевных страданий, размышлений и раздумий: Поглядите-ка, поглядите, каков сероватый тон! ... Пониже, вон там, под облачком... прелесть! С зеленоватым оттенком [3, 71]; Пойдут люди в иерковь: многим из них станет легче... Впрочем, помню, и мне легче становилось. Мальчиком был тогда [3, 95].

Еще один стилистический прием, часто встречающийся в прозе Гаршина, - перифраз: Утки громко закричали, одна из них хотела подхватить бедную спутницу на лету, но промахнулась (о лягушке) [3, 201]; «Прощайте, люди! Прощзайте, кровожсадные, кривляющцеся обезьяны!» [3, 94]; Конечно, многим может показаться раем и эта тюрьма после жалкого существования, которое они вели на воле (об оранжерее) [3, 82]; (о картине) $я$ - язва растущая! [3, 74]; ...пока ты пишешь картину - ты ху дожник, творещ; написана она - ты торгаш [3, 70].

Как свидетельствует проведенный нами анализ, в своих произведениях писатель с предельной честностью и реалистическим психологизмам создал яркие художественные образы. Автор «Красного цветка», по оценке многих исследователей, обладал человеческим состраданием, «великолепным чутьем боли» (А. П. Чехов). Язык гаршинских произведений, яркий и выразительный, обладает особенными качествами редкой эмоциональности и экспрессивности, реалистическим психологизмом, художественной детализацией, что в целом позволяет определить его творчество как яркий пример экспрессионизма в русской литературе.

\section{Список использованной литературы}

1. Виноградов В. В. О языке художественной литературы. - М.: Изд-во АН CCCP, 1957. $-358 \mathrm{c}$.

2. Гаршин В. М. Рассказы. - Л.: Худож. лит., 1978. - 320 с.

3. Гаршин В. М. Рассказы. - Л.: Худож. лит., 1986. -256 с.

4. Ефимов А. И. О языке художественных произведений. - М.: Учпедгиз, 1954. -288 с.

5. Ковалев В. П. Языковые выразительные средства русской художественной прозы. - К.: Вища шк., 1981. - 184 с. 
6. Мамонов В. А., Розенталь Д. Э. Практическая стилистика современного русского языка. - М.: Искусство, 1957. - 176 с.

7. Пустовойт П. Г. От слова к образу. - К.: Рад. шк., 1974. - 192 с.

8. Русские писатели. Библиограф. слов. [В 2 ч.]. Ч. І. А-Л / Редкол.: Б. Ф. Егоров и др.; Под ред. П. А. Николаева. - М.: Просвещение, 1990. - 432 с.

\section{Summary}

The article analyses the peculiarities of artistic speech of a famous Russian writer V. M. Garshin and defines the role of expressive means in his fiction. 